$\mathrm{Oz}$

$1-1-2018$

\title{
The Case for an Authentic Growth
}

Yen Ong

$5 G$ Studio

Follow this and additional works at: https://newprairiepress.org/oz

Part of the Architecture Commons

(c) (1) $9 \Theta$

This work is licensed under a Creative Commons Attribution-Noncommercial-No Derivative Works 4.0 License.

\section{Recommended Citation}

Ong, Yen (2018) "The Case for an Authentic Growth," Oz: Vol. 40. https://doi.org/10.4148/2378-5853.1585

This Article is brought to you for free and open access by New Prairie Press. It has been accepted for inclusion in Oz by an authorized administrator of New Prairie Press. For more information, please contact cads@k-state.edu. 
The Case for an Authentic Growth

\section{Yen Ong}

$5 G$ Studio

I have sold out since I graduated a little more than two decades ago. My idealistic, younger self would have patently condemned the choices my present self has made since then. Idealism would be the righteous position for a student of architecture to take, one who has been fed stories of famed architects realizing their architectural vision in no other way but theirs, proclaiming an absolute authenticity to their creation, or opting to be financially bankrupt rather than to compromise their talents in service of uninspiring commissions. That was then, and this is now: the authentic identity that drives one's body of work matures over time and is their inescapable reality.

In the year 2005, we launched 5G Studio at an opportunity offered through an unglamorous architectural design project. It was purely a business decision, my most significant sell-out, an ironic start for a company of friends who aspired to compete with the best designers in the world. The few years that followed did not offer much other than more challenges to our architectural idealism along with the financial resources to continue our business during the great recession of 2008. I visualized ourselves walking on a tightrope; we knew where we wanted to be but could not lose our balance to get there. There was not any guarantee, and even now, there will never be. The choices I made in practice remain my true identity; in retrospect, I make no apologies. The current practice of architecture has to insist upon an architectural authenticity without regard to other conflicting interests. Being certain and immovable is a disservice to an authentic growth.

We live in a time of overwhelming connectedness. Architects now have easy access to the works and ideas of their peers halfway across the globe, mostly those of the famous and celebrated, with a sprinkling of obscure but ingenious applications of research from other specialized disciplines. Outlets like ArchDaily, Dezeen, and many others flood the architectural minds with algorithmically aligned concept of what is current and new. The exposure and the sharing of ideas are productive yet bring forth challenges to the claim of authenticity, as they often reveal patterns of predictable conformity. The contemporary acceptance of the sharing economy and opensource knowledge helps to propel the profession forward and should be welcomed. However, a superficial appreciation of striking architectural images may diminish the authority of a designer's claim to authenticity as something that "looks like it" likely exists elsewhere. The authentic intention that drove the production of the visual representation and enabled the real construction may only be evident behind the scene.

I believe the authentic value of an architectural work to be crafted during the process of architectural creation through intents and technical resolutions that are guided by the

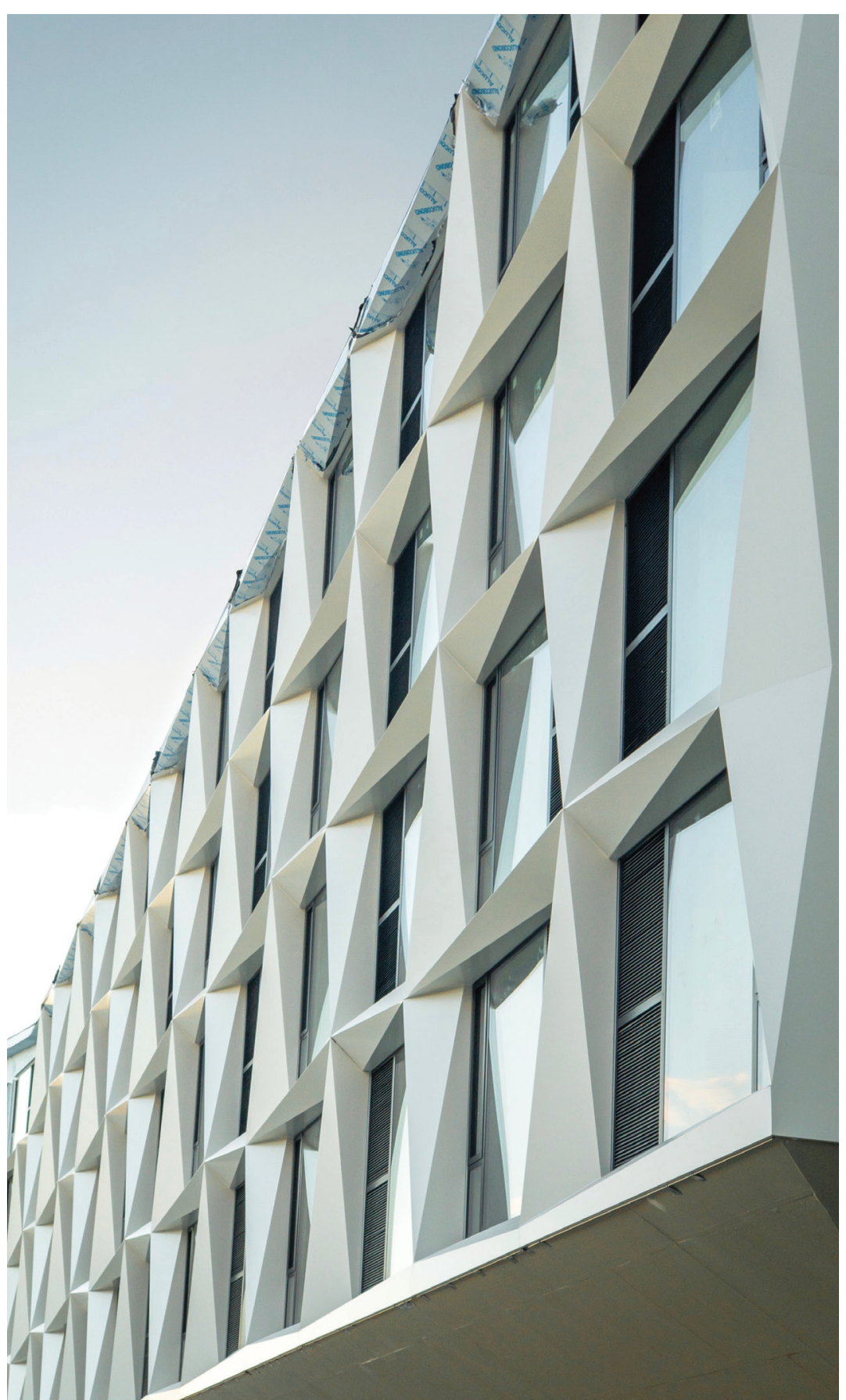




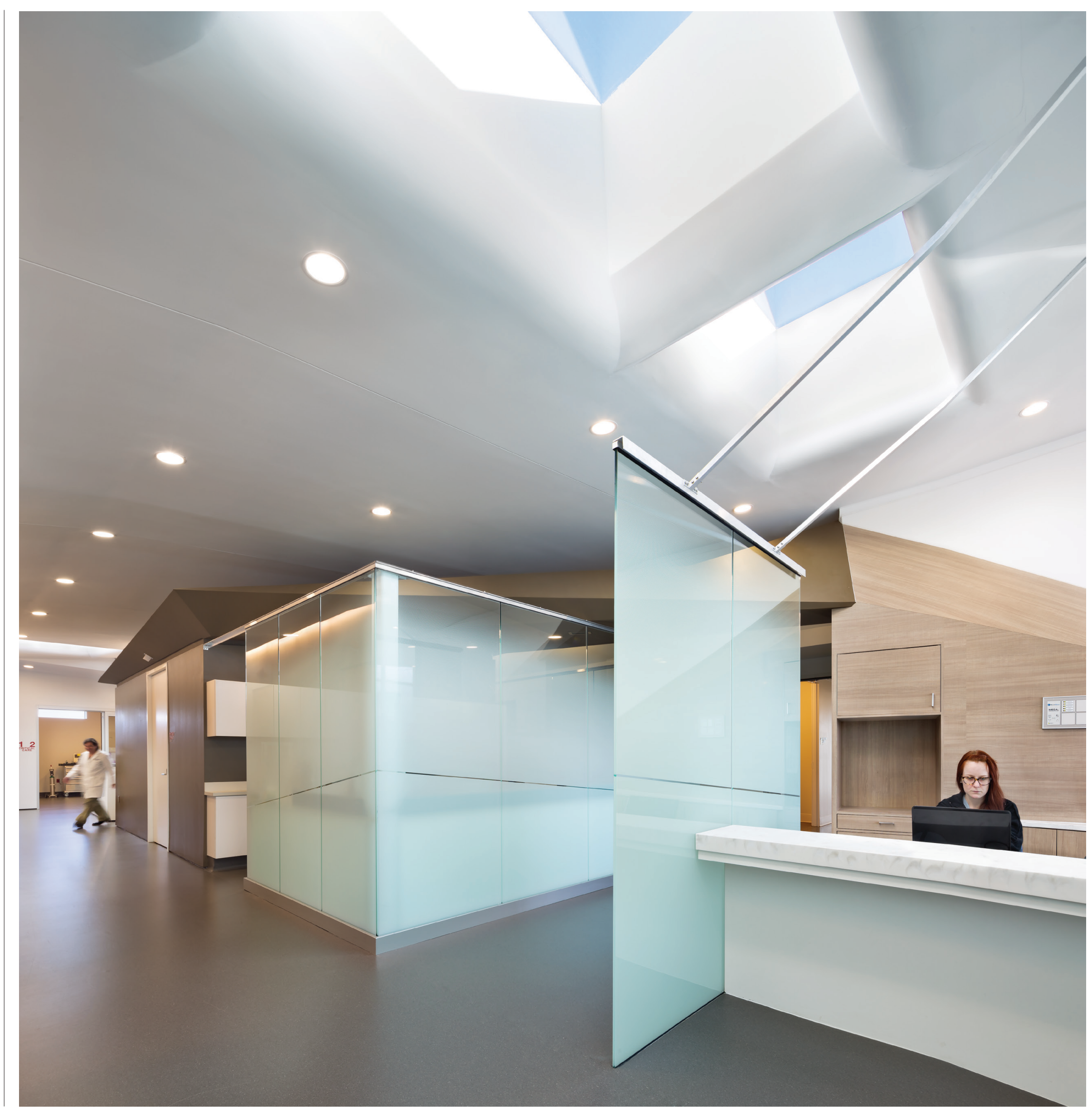



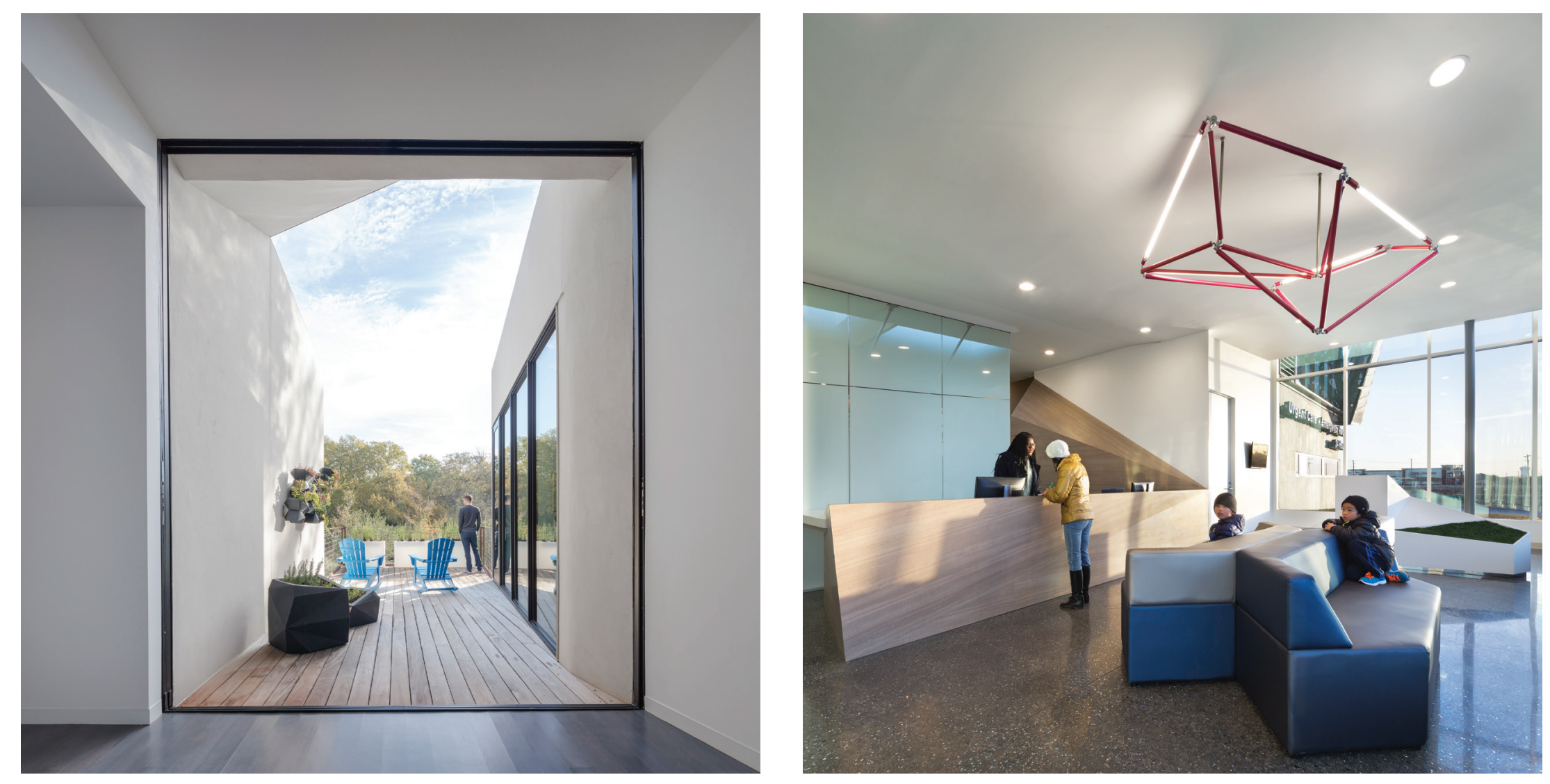

-

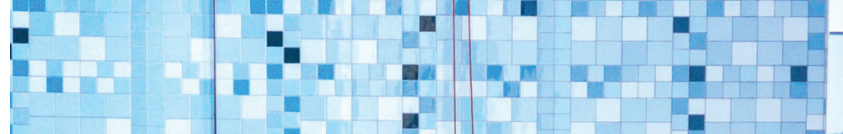

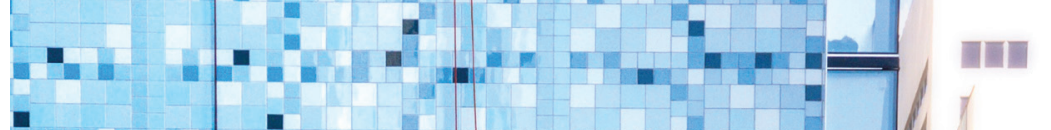

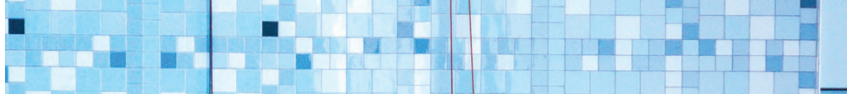

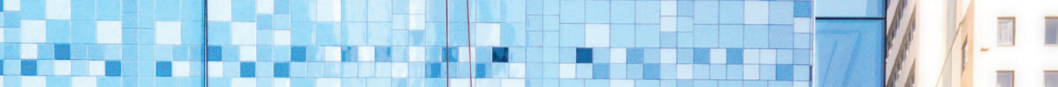

-

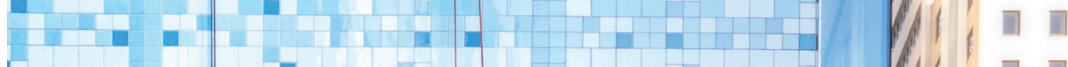

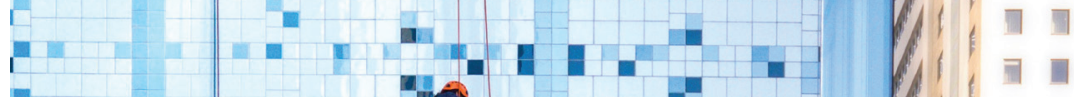

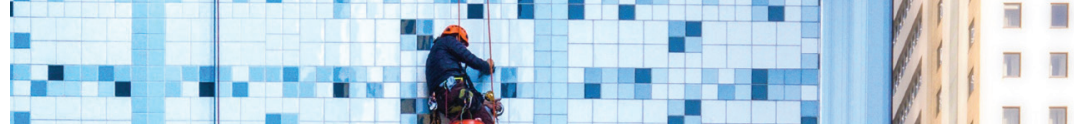

- 1 -

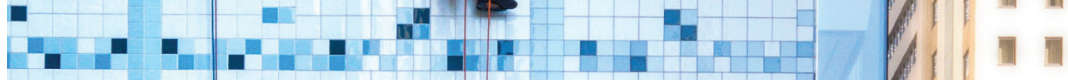

1

m in a

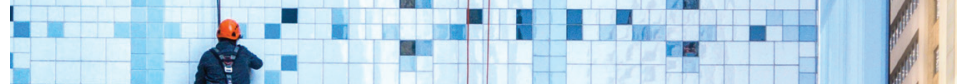

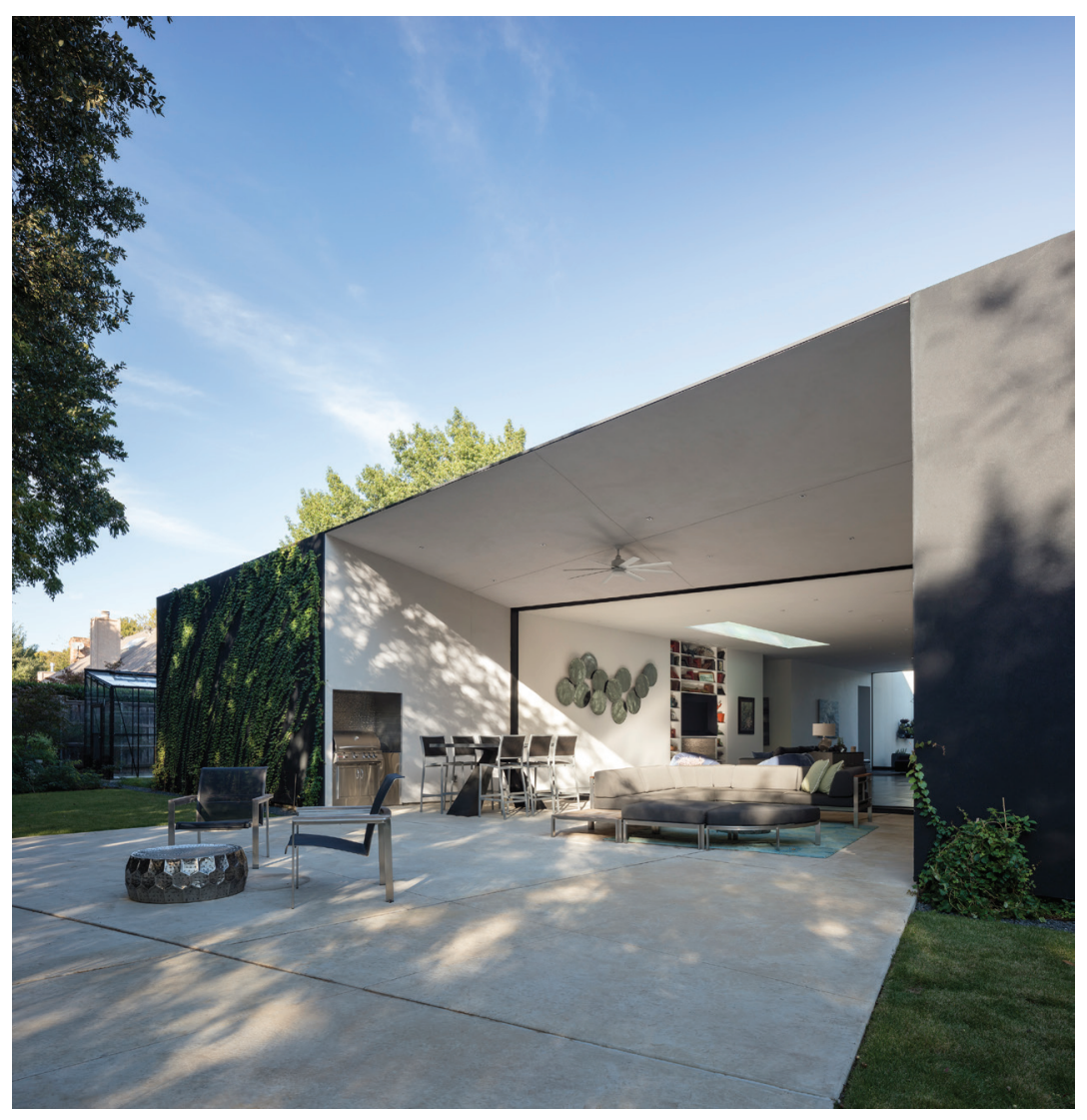




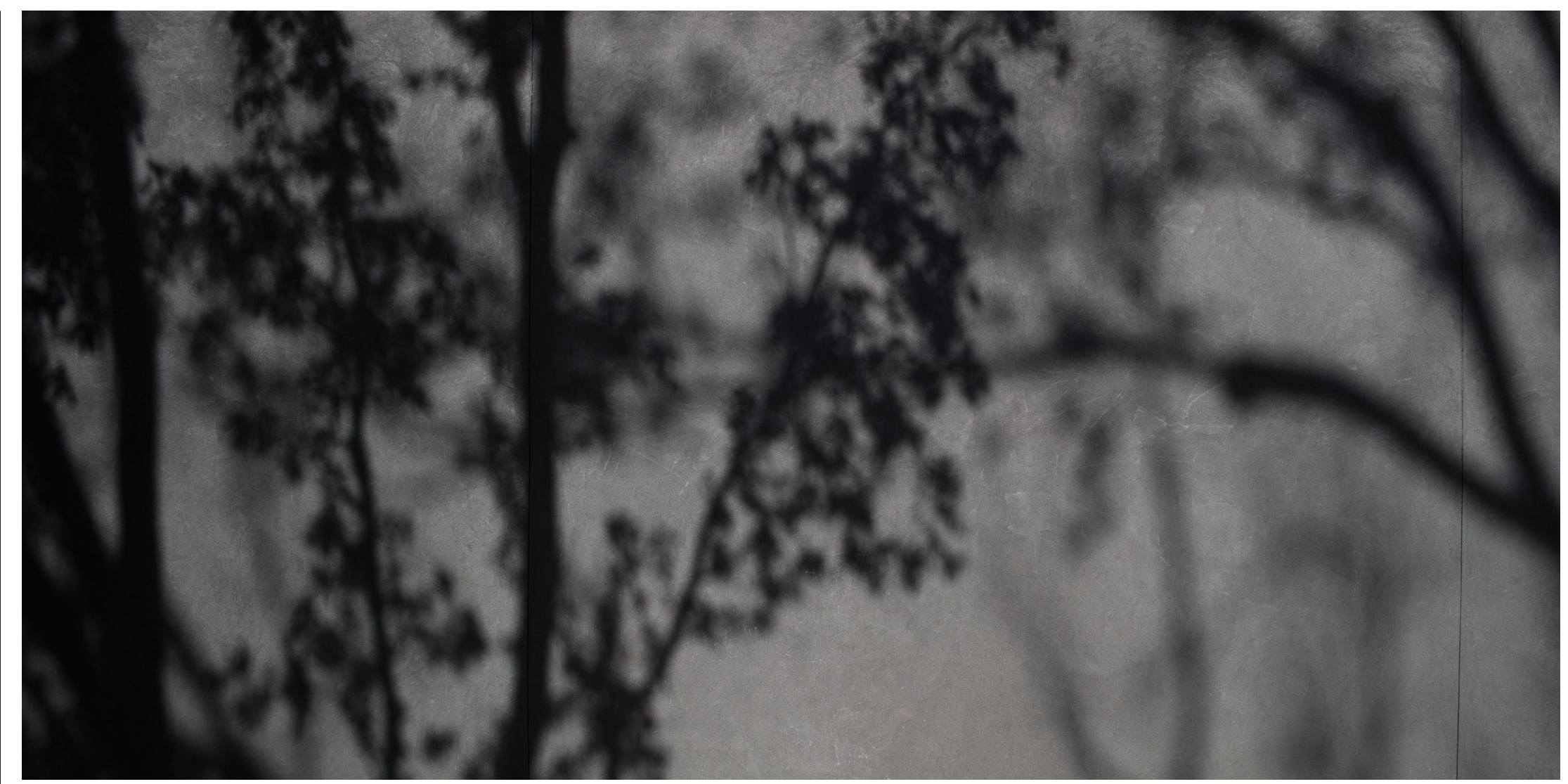

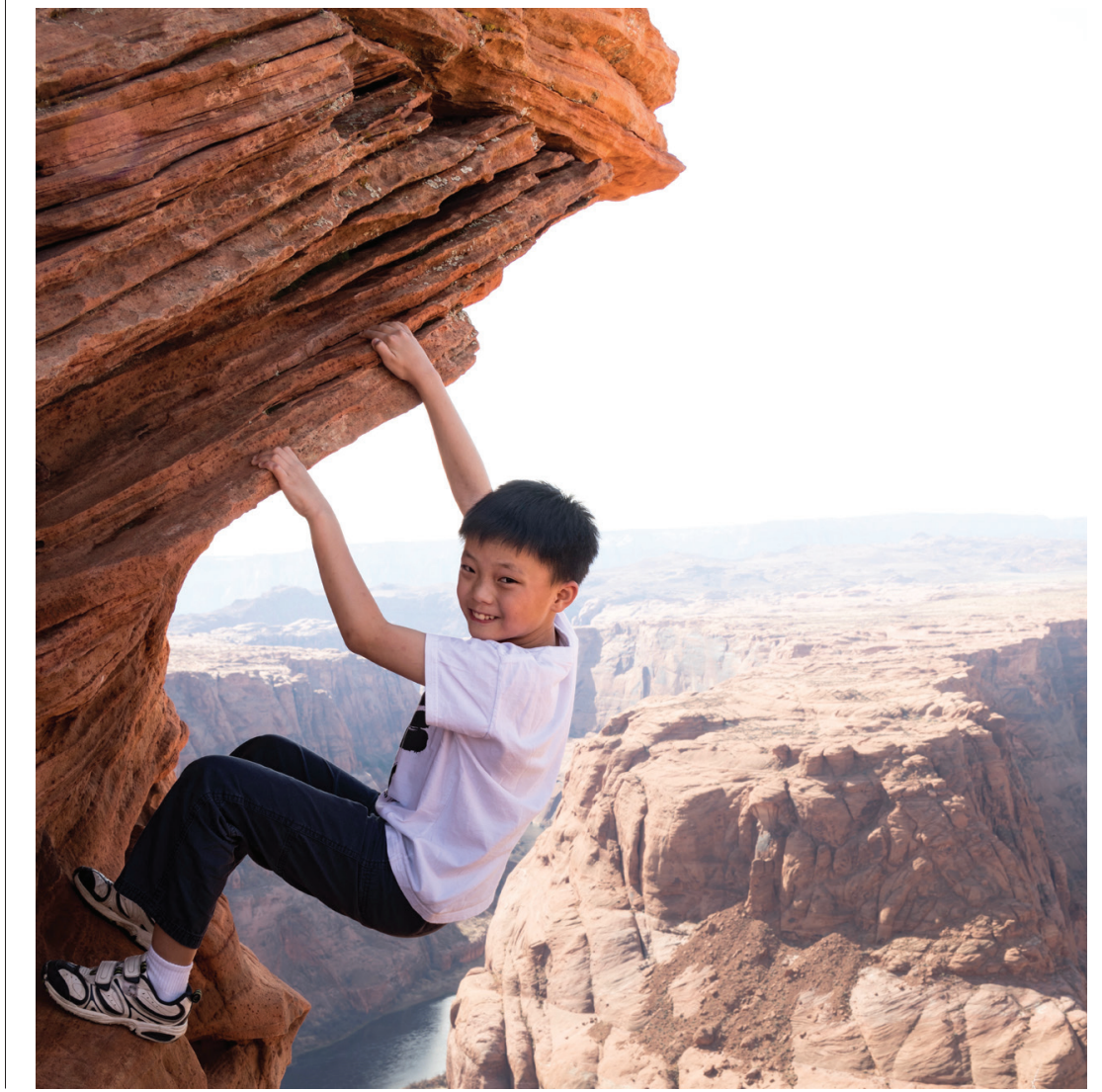

creator's mindset and identity at the time. My son, Ryu, was 30 weeks old when he was born in January 2007. Just past midnight, I was trailing an ambulance that was carrying my wife to a prominent Dallas area hospital. We were checked into the emergency department. There I was, in a dimly lit windowless room, my wife lying on a stretcher beside me, waiting for hours. When anxiety became too much, I would step out of the room and into a long fluorescent-lit deathly corridor, see no one, and find no relief. I had never felt more alone. Ryu was born safely at the crack of dawn. I went into the office later that morning and scrapped the schematic design of one of the first freestanding emergency room buildings in the country. The assignment was no longer intellectual; it was personal. After so many years, I finally learned that within the spaces we design, there will be stories written by real people. Producing an authentic work of ar- chitecture takes much more than the ability to compose beautiful forms and spaces; it takes a personal appreciation for the purpose and does not necessitate radical originality. More than anything, it takes sincerity.

Authentic growth requires a good amount of introspective uncertainty. It will have been helpful for more leaders in the profession to share the vulnerability beneath the cloak of their public success stories. A career will be a long journey where choices can lead down a path where one would or would not have liked to find oneself. You have to begin by believing in you; whatever may come be your authentic identity. 